\title{
An exploratory study of discrepancies between objective and subjective measurement of the physical activity level in female patients with chronic fatigue syndrome
}

Citation for published version (APA):

Vergauwen, K., Huijnen, I. P. J., Smeets, R. J. E. M., Kos, D., van Eupen, I., Nijs, J., \& Meeus, M. (2021). An exploratory study of discrepancies between objective and subjective measurement of the physical activity level in female patients with chronic fatigue syndrome. Journal of Psychosomatic Research, 144, [110417]. https://doi.org/10.1016/j.jpsychores.2021.110417

Document status and date:

Published: 01/05/2021

DOI:

10.1016/j.jpsychores.2021.110417

Document Version:

Publisher's PDF, also known as Version of record

\section{Document license:}

Taverne

\section{Please check the document version of this publication:}

- A submitted manuscript is the version of the article upon submission and before peer-review. There can be important differences between the submitted version and the official published version of record. People interested in the research are advised to contact the author for the final version of the publication, or visit the DOI to the publisher's website.

- The final author version and the galley proof are versions of the publication after peer review.

- The final published version features the final layout of the paper including the volume, issue and page numbers.

Link to publication

\footnotetext{
General rights rights.

- You may freely distribute the URL identifying the publication in the public portal. please follow below link for the End User Agreement:

www.umlib.nl/taverne-license

Take down policy

If you believe that this document breaches copyright please contact us at:

repository@maastrichtuniversity.nl

providing details and we will investigate your claim.
}

Copyright and moral rights for the publications made accessible in the public portal are retained by the authors and/or other copyright owners and it is a condition of accessing publications that users recognise and abide by the legal requirements associated with these

- Users may download and print one copy of any publication from the public portal for the purpose of private study or research.

- You may not further distribute the material or use it for any profit-making activity or commercial gain

If the publication is distributed under the terms of Article 25fa of the Dutch Copyright Act, indicated by the "Taverne" license above, 


\title{
An exploratory study of discrepancies between objective and subjective measurement of the physical activity level in female patients with chronic fatigue syndrome
}

\author{
Kuni Vergauwen $^{\text {a,b,c,d }}$, Ivan P.J. Huijnen ${ }^{\text {b,e }}$, Rob J.E.M. Smeets ${ }^{\text {b,f }}$, Daphne Kos ${ }^{\text {a,g,h }}$, \\ Inge van Eupen $^{a}$, Jo Nijs ${ }^{i, j}$, Mira Meeus ${ }^{c, d, k, *}$ \\ ${ }^{\text {a }}$ Department of Health Care, AP University College, Antwerp, Belgium \\ b Department of Rehabilitation Medicine, CAPHRI, Maastricht University, Maastricht, the Netherlands \\ ${ }^{\mathrm{c}}$ MOVANT, Department of Rehabilitation Sciences and Physiotherapy, University of Antwerp, Antwerp, Belgium \\ ${ }^{\mathrm{d}}$ Pain in Motion International Research Group, www.paininmotion.be, Belgium \\ ${ }^{\mathrm{e}}$ Adelante, Centre of Expertise in Rehabilitation and Audiology, Hoensbroek, the Netherlands \\ ${ }^{\mathrm{f}}$ CIR Revalidatie, Eindhoven, the Netherlands \\ ${ }^{\mathrm{g}}$ Department of Rehabilitation Sciences, KU Leuven-University of Leuven, Leuven, Belgium

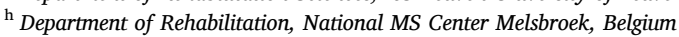 \\ ${ }^{\mathrm{i}}$ Pain in Motion group VUB (PAIN), Department of Physiotherapy, Human Physiology and Anatomy, Vrije Universiteit Brussel, Building F-Kima, Laarbeeklaan 103, BE- \\ 1090 Brussels, Belgium. \\ ${ }^{\mathrm{j}}$ Department of Physical Medicine and Physiotherapy, University Hospital Brussels, Belgium \\ ${ }^{\mathrm{k}}$ Department of Rehabilitation Sciences and Physiotherapy, Ghent University, Belgium
}

\section{A R T I C L E I N F O}

\section{Keywords:}

Assessment

Accelerometry

Chronic fatigue syndrome

Physical activity

Self-report

Validity

\begin{abstract}
A B S T R A C T
Objective: To explore the ability of a self-report activity diary to measure the physical activity level (PAL) in female patients with chronic fatigue syndrome (CFS) and whether illness-related complaints, health-related quality of life domains (HRQOL) or demographic factors are associated with discrepancies between selfreported and objectively measured PAL.

Methods: Sixty-six patients with CFS, recruited from the chronic fatigue clinic of a university hospital, and twenty matched healthy controls wore an accelerometer (Actical) for six consecutive days and registered their activities in an activity diary in the same period. Participants' demographic data was collected and all subjects completed the CFS Symptom List (illness-related complaints) daily and Short-Form-36 (HRQOL domains) during the first and second appointment.

Results: A significant, but weak association between the activity diary and Actical was present in patients with CFS $\left(r_{s}=0.376\right.$ and $\left.r_{s}=0.352 ; p<0.001\right)$ and a moderately strong association in healthy controls $\left(r_{s}=0.605\right.$; and $\left.r_{s}=0.644 ; p<0.001\right)$ between week and weekend days, respectively. A linear mixed model identified a negative association between age and the discrepancy between the self-reported and objective measure of PA in both patients with CFS and healthy controls.

Conclusion: The activity diary showed limited ability to register the PAL in female patients with CFS. The discrepancy between measures was not explained by illness-related complaints, HRQOL domains or demographic factors. The activity diary cannot replace objective activity monitoring measured with an accelerometer, but may provide additional information about the perceived activity.
\end{abstract}

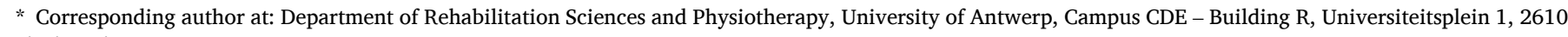
Wilrijk, Belgium.

E-mail addresses: kuni.vergauwen@ap.be (K. Vergauwen), ivan.huijnen@maastrichtuniversity.nl (I.P.J. Huijnen), r.smeets@maastrichtuniversity.nl

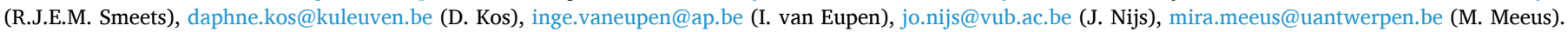




\section{Introduction}

In chronic fatigue syndrome (CFS), a condition characterized by persistent or relapsing debilitating fatigue lasting more than six months which is not alleviated by rest [1,2], both objectively measured (i.e. with accelerometry) [3] and self-reported [3,4] lower physical activity levels (PAL) have been found in comparison to healthy controls. Subjects with CFS mostly perform activities of mostly sedentary and light intensity $[4,6]$, which is similar to healthy adults $[4,5]$, but they perform less activities of moderate and high-intensity $[4,6]$. Additionally, large individual differences have been identified and suggested to be the result of two different coping strategies applied by patients with CFS, the pervasively passive and relatively active strategy, respectively [7]. The pervasively passive patients show avoidance behavior towards physical activity (PA) and become inactive, while the relatively active patients try to perform at pre-illness levels despite their complaints, which leads to an irregular activity pattern with an imbalance between activity and rest $[7,8]$. Because both subgroups show such different activity patterns, activity management programs that aim at improving patients' PAL need to be tailored to their individual coping strategy [7-9] by accurately estimating patients' PAL and pattern.

Use of objective activity monitor systems (i.e. accelerometers) is recommended $[7,8]$, but their psychometric properties depend on the device, how it is used, the studied population and type of activity [10-13]. Also, different calibration methods and cut-points for defining and categorizing physical activity intensities are often used [11,13-15]. Their psychometric properties are mostly investigated at group-level in healthy non-sedentary individuals $[10,13,16]$, but it is unclear if they are able to detect the amount and intensity of performed activities accurately in patients with CFS at an individual level [10,17]. Also, they do not provide detailed information about the type and context of the performed PA and give no insight into a patient's perceived PAL $[11,13]$.

Self-report measures are capable of registering this additional information and therefore offer complementary information on a patient's PAL not captured by an objective activity monitor system. Various studies suggest using multiple assessment methods simultaneously when measuring PAL, depending on the assessment goal(s) $[11,13]$. However, some considerations must be made when using self-report measures in patients with CFS. Previous research has established a weak relationship between objective and subjective PA measures [11,12,18] and, even though no clear trends regarding over- or underestimation have been identified [11], various factors have been hypothesized to potentially influence self-report. In self-report measures relying on recall, incorrect remembering could induce false reporting $[11,13]$, especially in patients with CFS often suffering from cognitive problems such as impairments in working memory, information processing speed, immediate and delayed recall [19]. Moreover, measures using general subjective interpretations about PA in CFS seem to reflect a patients' view about PA and may be biased by their cognitions about illness and disability causing them to estimate their own activity level inaccurately [7,18]. Unrealistic thoughts about their premorbid activity level and misjudgment of the activity level of healthy controls contribute to these incorrect cognitions and patients' tendency to report being inactive most of the time $[7,8]$. Results of previous studies $[18,20]$ also suggested fatigue to be related to discrepancies between self-report and objective measures. PAL and health-related quality of life (HRQOL), mainly physical domains, have been found to be significantly associated in healthy controls [21,22] with objective measures having a slightly higher association than selfreport measures [22]. Results indicate a discrepancy between selfreported and objectively reported PAL, but it has not been identified if perceived HRQOL itself is associated with the discrepancy between both measures. Finally, in healthy individuals reporting discrepancies exist between genders with, on average, females having a higher overestimation than males [11]. Associations with other sociodemographic factors have not been identified. Overall, studies investigating factors associated with discrepancies between both measures, and more specifically in patients with CFS, are scarce.

Because subjective activity measures are relevant for clinical practice, identification of a format that is capable of measuring the PAL similar to an objective activity monitor would be a significant asset. Because the relationship between self-report measures consisting of subjective and general interpretations of PA and relying on recall and objective activity measures are low, self-report measures encompassing detailed information about a patient's daily activities including the type, amount and intensity of the activity are recommended [8,23]. According to Terwee et al. (2010), the total activity counts generated by an accelerometer as outcome measure is the most optimal comparison to validate a measurement instrument that aims to measure total PA, due to lack of a 'gold' standard for PA [24].

This exploratory study primarily aims to evaluate the ability of a detailed self-report activity diary based on an instantaneous registration of activities to measure the PAL in female patients with CFS by comparing it to an accelerometer, and to compare potential discrepancies between subjective and objective measures in patients with CFS versus healthy controls.

The correlation coefficient between both measures should be $\geq 0.50$ for an acceptable convergent validity [24].

In case of discrepancies between both measures, it will be investigated whether and which illness-related complaints, HRQOL domains or demographic factors are associated with these discrepancies.

\section{Method}

\subsection{Participants}

Patients were recruited through the chronic fatigue clinic of the department of Human Physiology and Rehabilitation Sciences of the Vrije Universiteit Brussel in Brussels, Belgium.

Patients had to be (1) Dutch speaking, (2) female, (3) aged between 18 and 65 years, (4) diagnosed with CFS according to the international criteria [2].

All patients were diagnosed with CFS by the same physician of internal medicine and underwent an extensive medical evaluation including a clinical examination, analyses of the medical history, exercise tolerance test and routine laboratory assessment. If judged necessary by the physician, additional psychiatric, neurological, gynaecological, endocrinological, cardiac and/or gastrointestinal examinations were performed. A positive result on any of the examinations led to the exclusion of patients according to the diagnostic criteria [2]. If all inclusion criteria were met, patients were contacted by telephone by a researcher to inform them on the present study and invite them for participation. If they consented, two appointments were made, always on a Monday or Tuesday, with one week between both consultations. Patients also received an information brochure by mail or e-mail.

CFS patients were age-matched to healthy controls to evaluate whether the association between the self-reported and objective PAL established in this study is CFS-specific. They were recruited from hospital personnel, personnel from the College University of Antwerp (Department of Healthcare) and social network of researchers. Selection was based on following criteria: Dutch speaking, female, aged between 18 and 65 years, sedentary.

A sedentary lifestyle was defined as having a predominant sitting or standing job and performing moderate or intensive physical activity less than three hours per week [25].

\subsection{Procedure}

During first consultation, both patients with CFS and healthy controls were informed again about all aspects of the study, received an information brochure and were asked to sign an informed consent in case of agreement. This study was approved by the Medical Ethics Commission of the Academic Hospital of the Vrije Universiteit Brussel 
(University Hospital Vrije Universiteit Brussel; O.G. 016)

Participants' demographic data were collected during the first appointment and all participants were asked to complete a test battery (standardized test order) with the CFS Symptom List and the Short Form Health Survey-36 (SF-36). After completion, the accelerometer (Actical) and activity diary were explained and provided.

At the second appointment one week later participants handed in the Actical and activity diary and completed the test battery a second time.

\subsection{Measures}

\subsubsection{Patient characteristics}

Age and disease duration were collected during the first appointment.

\subsubsection{Objectively measured physical activity}

Objective measurement of PA was measured with the Actical (Mini Mitter, Bend, OR), an omnidirectional accelerometer. The device weighs $17 \mathrm{~g}$ and measures $28 \mathrm{~mm} \times 27 \mathrm{~mm} \times 10 \mathrm{~mm}$. The Actical has an output called 'activity counts' (AC), which is a result of voltage generated by the sensor and produced by a change in amplitude and frequency of movements [16]. In this study, AC are calculated in 1-min intervals. Total AC per day were calculated and then divided by 1440 to obtain AC/min.

At the start, gender, age, height and weight of the participant and start date and time were entered into the Actical. Measurement started after attachment of the Actical on the non-dominant wrist of the participant.

Participants were instructed to wear the Actical $24 \mathrm{~h} /$ day for six consecutive days until their second consultation, even when sleeping or bathing. The Actical is waterproof and resistant to normal water exposure up to $1-\mathrm{m}$ depth for $30 \mathrm{~min}$. The Actical is validated for measuring activity energy expenditure in healthy persons $[16,26]$.

In patients with CFS, three activity patterns can be distinguished: pervasively passive $[7,8,27]$, pervasively active $[7,8,27]$ and moderately active $[7,8]$. Both patients with CFS and healthy controls were categorized into one of the aforementioned activity patterns based on the mean total AC of the CFS sample (mean $=242.80 \mathrm{AC} / \mathrm{min}$ ) and the following criteria:

Pervasively passive (PP): Total AC of all five measured days are below mean total AC of the CFS sample [7,27].

Pervasively active: Total AC of all five measured days are above the mean total AC of the CFS sample [7,27].

Moderately active (MA): There is no PP or PA pattern [7].

\subsubsection{Self-reported physical activity}

The activity diary consists of a paper version template in which performed activities per day should be registered. For each activity the kind of activity, starting time, end time and total duration need to be recorded. Participants were instructed to start recording their activities the morning after their first consultation until the evening before the second appointment to have data of six full days, including week and weekend days. Activities had to be registered at the beginning of each activity to avoid inaccurate registration due to recall. During the second consultation, the researcher manually checked all activities registered in the activity diary to correct errors when the diary was not completed according to the instructions and to minimize missing data by filling in gaps if possible (based on recall).

Researchers calculated the Metabolic Equivalent of Task-value (MET), an expression of the intensity of PA relative to an individual's resting energy expenditure, for each activity reported in the activity diary using the Compendium of Physical Activities Tracking Guide [28]. Microsoft Excel was used to calculate the total MET per day, which were then divided by 1440 to obtain MET/min.

\subsubsection{CFS symptom list}

Self-reported symptom severity was measured daily with the CFS Symptom List. It refers to the past $24 \mathrm{~h}$ [29] and includes 19 symptoms most frequently reported by patients with CFS. The measure assesses symptom severity with a 100 -mm visual analogue scale (VAS) per symptom and total symptom severity can be calculated [29,30]. These symptom severity scores were used for this study. The VAS has acceptable psychometric properties in various chronic disease populations [31-33].

\subsubsection{Health related quality of life}

The SF-36 (version 1) was used to measure HRQOL. It contains 36 items on eight subscales: physical functioning, role limitations due to physical health, role limitations due to emotional problems, energy/ fatigue, emotional wellbeing, social functioning, pain, general health and measures health change. Scores range from 0 to 100 and a higher score indicates a higher HRQOL [34]. The Dutch language version is reliable and valid [35].

\subsection{Statistical analysis}

Data were analyzed in SPSS version 27 and R. Non-parametric statistics were used due to non-normal distributions of both groups. Sample descriptive characteristics and PAL outcomes of both measures (AC and MET) for week and weekend days were compared using Mann-Whitney $U$ tests.

The strength of the association between the Actical (AC) and activity diary (MET) was studied using Spearman correlation coefficients for week- and weekend days separately, because of frequently observed differences between performed activities during week- and weekend days [36]. Correlation coefficients between AC and MET were calculated for both the total case and control group separately and per activity pattern (PP, MA, pervasively active).

To evaluate which factors are associated with the potential overestimation or underestimation of the PAL by self-report (discrepancy) in patients with CFS relative to healthy controls, first linear regression was carried out with AC as dependent variable and MET as independent variable for both cases and controls. Second, the residuals after regression, an indication of the relative margin of error in the ability of the activity diary to predict the PAL in this sample, were entered as dependent variable in the linear mixed model to identify factors associated with the discrepancy between self-reported and objective activity monitoring. Daily measured symptom severity per symptom and total symptom severity (CFS Symptom List), HRQOL at baseline (SF-36 subscale scores), age and disease duration were entered as independent variables in the linear mixed model.

For each linear mixed model, the significance of the fixed effect was tested using a likelihood ratio test. Due to the multitude of variables tested, that could lead to an increased type 1 error, a false discovery rate (FDR) analysis was carried out [37]. Finally, case-control status was included in the final model to identify whether the associated factor(s) were influenced by differences in the factor(s) between patients with CFS and healthy controls and/or an interaction effect between the associated factor(s) and case-control status that could (partially) account for the difference in the strength of the association between both measures for cases and controls. Significance level for all analyses was set at $p \leq 0.05$.

\section{Results}

\subsection{Participants}

A total of 66 female patients with CFS and 20 female healthy controls participated. Table 1 presents descriptive statistics for age, disease duration, AC and MET for weekdays and weekend days.

Both groups did not differ for age $\left(\right.$ median $_{\mathrm{CFS}}=42$; median $_{\text {controls }}=$ 
Table 1

Sample descriptive statistics.

\begin{tabular}{|c|c|c|c|c|c|c|c|c|c|c|c|}
\hline & \multicolumn{3}{|l|}{ CFS } & \multirow[b]{2}{*}{$\mathrm{M}^{\mathrm{c}}$} & \multicolumn{3}{|c|}{ Healthy controls } & \multirow[b]{2}{*}{$\mathbf{M}^{\mathrm{c}}$} & \multirow[b]{2}{*}{$\mathrm{U}^{\mathrm{c}}$} & \multirow[b]{2}{*}{$\mathrm{Z}^{\mathrm{c}}$} & \multirow[b]{2}{*}{$\mathrm{p}$} \\
\hline & $\mathrm{n}$ & Median (range) & IQR & & $\mathrm{n}$ & Median (range) & IQR & & & & \\
\hline Age (years) & $66^{\mathrm{a}}$ & $42(20-62)$ & $37-47$ & 43.67 & $20^{\mathrm{a}}$ & $43(24-60)$ & $34-47$ & 42.93 & 648.5 & -0.118 & 0.91 \\
\hline Disease duration (months) & $66^{\mathrm{a}}$ & $72(5-360)$ & $36-120$ & & & & & & & & \\
\hline $\begin{array}{c}\mathrm{AC}(\mathrm{AC} / \mathrm{min}) \\
\text { (weekday) }\end{array}$ & $198^{\mathrm{b}}$ & $\begin{array}{l}231.3 \\
(23.3-694)\end{array}$ & $177.2-308.7$ & 123.99 & $60^{\mathrm{b}}$ & $\begin{array}{l}264.9 \\
(121.7-644.4)\end{array}$ & $188.1-372.4$ & 147.67 & 4850 & -2.153 & 0.03 \\
\hline $\begin{array}{l}\mathrm{AC}(\mathrm{AC} / \mathrm{min}) \\
\quad \text { (weekend day) }\end{array}$ & $132^{\mathrm{b}}$ & $\begin{array}{l}213.1 \\
(32.2-532.3)\end{array}$ & $170-287.1$ & 84.77 & $40^{\mathrm{b}}$ & $\begin{array}{l}218.9 \\
(97-533.2)\end{array}$ & $168.8-336.3$ & 92.20 & 2412 & -0.826 & 0.41 \\
\hline $\begin{array}{l}\text { MET (MET/min) } \\
\text { (weekday) }\end{array}$ & $198^{\mathrm{b}}$ & $\begin{array}{l}1.42 \\
(1.01-2.41)\end{array}$ & $1.31-1.52$ & 119.33 & $60^{\mathrm{b}}$ & $\begin{array}{l}1.50 \\
(1.19-2.05)\end{array}$ & $1.41-1.68$ & 163.07 & 3925.5 & -3.978 & 0.003 \\
\hline $\begin{array}{r}\text { MET (MET/min) } \\
\text { (weekend day) }\end{array}$ & $131^{\mathrm{b}}$ & $\begin{array}{l}1.35 \\
(0.96-2.71)\end{array}$ & $1.26-1.46$ & 80.81 & $40^{\mathrm{b}}$ & $\begin{array}{l}1.41 \\
(1.15-2.60)\end{array}$ & $1.32-1.67$ & 102.99 & 1940.5 & -2.479 & 0.02 \\
\hline
\end{tabular}

$\mathrm{CFS}=$ chronic fatigue syndrome; $\mathrm{AC}(/ \mathrm{min})=$ activity counts (per minute); $\mathrm{MET}(/ \mathrm{min})=$ metabolic equivalent of task (per minute); IQR = interquartile range.

a number of participants.

b number of measurements (five measurements per participant for AC and MET; three weekdays and two weekend days).

c Mann-Whitney $U$ test comparing age, AC and MET between patients with CFS and healthy controls for weekdays and weekend days; M = mean rank.

$43 ; p=0.91)$.

Patients with CFS had a significantly lower PAL compared to healthy controls for MET for weekdays (median $_{\mathrm{CFS}}=1.42$; median $_{\text {controls }}=1.50$; $U=3925.5, p=0.003)$ and weekend days $\left(\right.$ median $_{\mathrm{CFS}}=1.35$ median $_{\text {controls }}=1.41 ; U=1940.5, p=0.02$ ), and for AC for weekdays only $\left(\right.$ median $_{\mathrm{CFS}}=231.3 ;$ median $_{\text {controls }}=264.9 ; U=4850, p=0.03$ ) (Table 1).

A significantly higher PAL for weekdays in comparison to weekend days in patients with CFS (median $_{\text {week }}=1.42 ;$ median $_{\text {weekend }}=1.35 ; U$ $=10,142, p=0.001)$ and in healthy controls $\left(\right.$ median $_{\text {week }}=1.50$; median $_{\text {weekend }}=1.41 ; U=914.5, p=0.04$ ) was identified for registered MET, but not for AC (Table 2).

\subsection{Comparison of self-reported and objectively measured PA}

Table 3 presents Spearman correlation coefficients between the activity diary and Actical. A significant, but weak association was found for patients with CFS for both weekdays $\left(\mathrm{r}_{\mathrm{S}}=0.376, p<0.001\right)$ and weekend days $\left(r_{S}=0.352, p<0.001\right)$. In the healthy control group, however, there was a significant and moderately strong association for both weekdays $\left(r_{\mathrm{S}}=0.605 ; \mathrm{p}<0.001\right)$ and weekend days $\left(\mathrm{r}_{\mathrm{S}}=0.644 ; \mathrm{p}\right.$ $<0.001)$.

The association between both measures was highest for CFS patients for the MA group (45\%) ( $\left.r_{S}=0.333, p=0.001\right)$ followed by the PP group $(35 \%)\left(r_{S}=0.254, p=0.04\right)$ both for weekdays only. In healthy controls, the highest association was for the PP group (25\%) for both weekdays $\left(\mathrm{r}_{\mathrm{S}}=0.886, \mathrm{p}<0.001\right)$ and weekend days $\left(\mathrm{r}_{\mathrm{S}}=0.806, p=\right.$ $0.005)$, followed by the MA group (50\%) for weekdays only $\left(r_{S}=0.503\right.$, $\mathrm{p}=0.005$ ). There was no significant association between both measures for the pervasively active group in both CFS patients (20\%) and healthy controls (25\%).

\subsection{Factors associated with discrepancies between self-reported and objectively measured $P A$}

Age was negatively associated with discrepancies between the activity diary and Actical (unstandardized residual) in both patients with CFS and healthy controls (Table 4). This result indicates that younger persons tend to underestimate their PAL and older persons tend to overestimate their PAL with an activity diary. The association remained significant after controlling for case-control status $(p=0.005)$. There was no interaction between age and case-control status $(p=0.82)$ indicating that the association between age and the discrepancy did not differ between patients with CFS and healthy controls. Individual symptom severity and total symptom severity (CFS Symptom List), HRQOL at baseline (SF-36 subscale scores) and disease duration were not significantly associated with discrepancies between the activity diary and Actical.

\section{Discussion}

Patients with CFS had a lower PAL in comparison to healthy controls according to the activity diary for both weekdays and weekend days, and the Actical for weekdays only. In healthy controls, the association between the activity diary and Actical was significant and moderately strong. In patients with CFS the association was also significant, but weak, suggesting that female patients with CFS are less capable than healthy persons of accurately registering their PAL. Linear mixed model analysis only identified a significant and negative association between age and discrepancies between both measures in patients with CFS and

Table 2

Mann-Whitney U test comparing AC and MET between weekdays and weekend days for patients with CFS and healthy controls.

\begin{tabular}{|c|c|c|c|c|c|c|c|c|}
\hline & & $\mathrm{n}^{\mathrm{b}}$ & Median & IQR & $\mathbf{M}^{\mathrm{c}}$ & $\mathrm{U}^{\mathrm{c}}$ & $\mathrm{Z}^{\mathrm{c}}$ & $\mathrm{p}$ \\
\hline \multicolumn{9}{|c|}{$\operatorname{CFS}(n=66)^{\mathrm{a}}$} \\
\hline \multirow[t]{2}{*}{ AC } & weekday & 198 & 231.3 & $177.2-308.7$ & 170.92 & 11,994 & -1.265 & 0.20 \\
\hline & weekend day & 132 & 213.1 & $170-287.1$ & 157.36 & & & \\
\hline \multirow[t]{2}{*}{ MET } & week day & 198 & 1.42 & $1.31-1.52$ & 179.28 & 10,142 & -3.348 & 0.001 \\
\hline & weekend day & 131 & 1.35 & $1.26-1.46$ & 143.42 & & & \\
\hline \multicolumn{9}{|c|}{ Healthy controls $(n=20)^{\mathrm{a}}$} \\
\hline \multirow[t]{2}{*}{$\mathrm{AC}$} & week day & 60 & 264.9 & $188.1-372.4$ & 53.75 & 1005 & -1.372 & 0.17 \\
\hline & weekend day & 40 & 218.9 & $168.8-336.3$ & 45.63 & & & \\
\hline \multirow[t]{2}{*}{ MET } & week day & 60 & 1.50 & $1.41-1.68$ & 55.26 & 914.5 & -2.009 & 0.04 \\
\hline & weekend day & 40 & 1.41 & $1.32-1.67$ & 43.36 & & & \\
\hline
\end{tabular}

$\mathrm{CFS}=$ chronic fatigue syndrome; $\mathrm{AC}=$ activity counts; MET $=$ metabolic equivalent of task; IQR $=$ interquartile range.

${ }^{a}$ number of participants.

b number of measurements (five measurements per participant for AC and MET; three weekdays and two weekend days).

c Mann-Whitney U test comparing age, AC and MET between weekdays and weekend days for patients with CFS and healthy controls; M = mean rank. 
Table 3

Spearman correlation coefficients between subjectively measured MET and objectively measured AC for weekdays and weekend days.

\begin{tabular}{|c|c|c|c|c|c|c|c|c|}
\hline & & & \multicolumn{6}{|c|}{ Actical } \\
\hline & & & \multicolumn{3}{|l|}{ CFS } & \multicolumn{3}{|l|}{$\mathrm{HC}$} \\
\hline & & & $\mathrm{n}$ & AC (week) & AC (weekend) & $\mathrm{n}$ & AC (week) & AC (weekend) \\
\hline \multirow[t]{8}{*}{ Diary } & Total group & MET (week) & 66 & $0.376^{* *}$ & & 20 & $0.605^{* *}$ & \\
\hline & & MET (weekend) & $66^{\mathrm{a}}$ & & $0.352^{* *}$ & 20 & & $0.644^{* *}$ \\
\hline & PP & MET (week) & 23 & $0.254 *$ & & 5 & $0.886^{* *}$ & \\
\hline & & MET (weekend) & 23 & & 0.279 & 5 & & $0.806^{\text {*⿰冫欠 }}$ \\
\hline & $\mathrm{PA}$ & MET(week) & 13 & 0.206 & & 5 & 0.266 & \\
\hline & & MET (weekend) & 13 & & 0.149 & 5 & & 0.042 \\
\hline & MA & MET (week) & 30 & $0.333^{* *}$ & & 10 & $0.503^{* *}$ & \\
\hline & & MET (weekend) & $30^{\mathrm{a}}$ & & 0.249 & 10 & & 0.293 \\
\hline
\end{tabular}

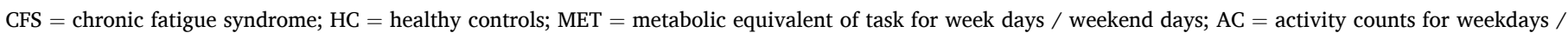
weekend days; $\mathrm{PP}=$ pervasively passive; $\mathrm{PA}=$ pervasively active; $\mathrm{MA}=$ moderately active.

a $\mathrm{MET}=\mathrm{n}-1$.

* $p<0.05$.

$p<0.01$.

Table 4

Linear mixed model summary of associations with the relative margin of error (unstandardized residual) between AC and MET in patients with CFS and healthy controls.

\begin{tabular}{lllll}
\hline Variable & $\mathrm{B}$ & $95 \% \mathrm{CI}$ & $\mathrm{p}$ & $\mathrm{q}$ \\
\hline Age & -2.8 & $-4.75 ;-0.86$ & 0.005 & 0.08 \\
\hline
\end{tabular}

$\mathrm{B}=$ unstandardized beta coefficient; $\mathrm{CI}=$ confidence interval; $\mathrm{q}=$ adjusted $p$ values using false discovery rate approach.

healthy controls and the association did not differ for both groups. This indicates that younger persons tend to underestimate their PAL and older persons tend to overestimate their PAL with an activity diary. The influence of age is only $2.8 \mathrm{AC} / \mathrm{min}$ per year increase in age.

When comparing the association between both measures based on the three subgroups of activity patterns identified in previous research, a significant association between both measures was present for the PP and MA group in both patients with CFS and healthy controls, but not for the pervasively active subgroup. These results indicate that there are additional factors that influence the association between both measures in the pervasively active group. These subgroups could not be analyzed further due to the small number of participants per subgroup, but this finding provides an additional point of attention for future research. A recent study proposed two criteria to identify an additional activity pattern in patients with CFS, i.e. boom and bust pattern [26]. In our patient sample, only one of the participants (2\%) who was not already classified into the PP or pervasively active group could be identified with a boom and bust pattern based on the proposed criteria, in contrast to $30 \%$ of the participants of the study of King et al. (2020) [26]. Even though our patient group $(n=66)$ is significantly smaller than this study ( $n=579$ ), it could be that the proposed criteria are not completely applicable to the total CFS population. It could also be that our period for activity recording, which was 5 days (although including week and weekend days), was too short to correctly identify all different activity patterns adopted by patients with CFS, as discussed by King et al. (2020) who had an average recording period of 3 to 7 days [26]. Since the correct identification of a patient's activity pattern is important to tailor the activity management program to their individual coping strategy, these concerns require further attention in future studies.

The above findings suggest that the activity diary and Actical do not measure the same parameters of PA and cannot replace one another. These results are in accordance with previous studies comparing selfreport to direct measures indicating that PA measured by self-report measures should be interpreted with caution, because it does not seem to be an accurate reflection of actual behavior [7,11]. Additionally, selfreported improvements, e.g. decrease in fatigue, are not always reflected by objective improvements, e.g. increase in PAL [38,39]. Therefore, objective measures, i.e. accelerometers, seem most suitable to use in clinical practice and research when the aim is to identify patients' PAL and activity pattern and objectively measure improvements in PAL $[7,9]$. Prevention of post-exertional malaise (PEM), the exacerbation of symptoms after exertion, is also important in patients with CFS, because PEM causes longer resting periods after exertion [7,40,41] and avoidance of activities which leads to a passive activity pattern [42]. Objective assessment of patients' activity level and pattern is therefore important to tailor activity management programs to the patient's individual coping strategy aimed at attaining and maintaining a regular, balanced activity pattern allowing the patient to perform meaningful activities of daily living, enable participation and prevent PEM $[9,42,43]$. The significant and moderately strong associations between both measures in healthy controls indicate that, when used complementary, a more comprehensive view of a person's PAL could be obtained. The Actical could capture more incidental activities and those of lower intensity, while the activity diary offers more specific information on the type and context of the performed activity [11,13,23]. A person's perceived difficulty of the performed activity was currently not a part of the activity diary, but could provide even more information to the researcher [11]. Therefore, self-report measures can be used in addition to objective measures to gain more insight into a patient's daily routine and gather contextual factors about the performed activities facilitating the formulation of an individualized activity management program including patients' meaningful activities of daily living [9].

Whether patients registered each activity according to the instructions to exclude inaccurate reporting based on recall and feasibility of the activity diary from a patient's perspective were both not examined. It was also not examined whether patients (previously) underwent any treatment focusing on PA or experienced illness-related cognitions that influenced their perception of PA [38,42] and consequently their self-reported PA. Future research should therefore investigate patients' reporting behavior and feasibility of the activity diary, and take PA related treatment and illness-related cognitions into account when exploring factors associated with the discrepancy between objective and self-report PAL. A digitalized activity diary based on experience sampling that yields regular reminders during the day requiring registration of the current performed activity could be of additional value [44].

None of the included factors could explain the discrepancy between both measures in patients with CFS relative to healthy controls, suggesting that there are other factors associated with the discrepancy that have not been investigated in this study. One possible factor could be mood. In patients with chronic low back pain, a lower PAL was reported by patients with a higher depression score and depression was significantly associated with the discrepancy found between self-report and objectively measured PA [45]. In patients with major depressive 
disorder (MDD), discrepancies between self-report questionnaires and objective measures of PA have been identified, suggesting that selfreport measures do not reflect actual PAL [46]. The proportion of patients with comorbid non-psychotic or non-melancholic MDD in our sample was not measured. This is a significant limitation considering it is an accepted comorbidity according to the CDC-94 criteria that could (partly) explain the found discrepancy between measures. In addition, patients with non-psychotic, non-melancholic MDD or anxiety engage in high levels of sedentary behavior and have a lower PAL compared to healthy controls [46,47], which could explain the different activity patterns in patients with CFS. The association between comorbid psychiatric disorders and discrepancies between objective and subjective measures of PA should be investigated further in patients with CFS.

This study has several additional limitations. First, different output variables were used to compare the activity diary to the Actical. Ideally, the output variable MET would have been used for both measures to allow direct comparison, but this included some limitations. The algorithm behind the calculation of MET-values and cut-points for the intensity categories of the Actical is unknown and these differ across devices and populations [13-15]. This causes ambiguity on how to analyze the collected data appropriately $[13,15]$. In addition, individual estimations of physical activity energy expenditure are often associated with large errors. Comparing MET-values across measurement instruments could therefore lead to misinterpretation of the results. The large errors also prevent the use of accelerometers to estimate changes in PA in response to activity management programs [15], which is an important goal of CFS rehabilitation. It is recommended that raw acceleration signals are collected and saved to prevent errors due to conversion into alternative variables (i.e. AC, MET) and allow comparison across populations and measures [48]. Additionally, the Compendium of Physical Activity used to calculate MET values is developed based on the energy expenditure of healthy individuals [28], but these values could be different for patients with CFS due to altered physiological capacities $[13,49,50]$. Previous research in healthy persons also found more discrepancies between self-report and direct measures in categories of higher intensity with self-report overestimating activities performed of vigorous intensity [11], suggesting self-report is less capable of accurately registering these activities. In contrast, accelerometers have been found to miss or misclassify certain activities depending on their placement and they do not take environmental and contextual factors, such as the terrain or added strain of carrying objects, into account when measuring activity intensities $[11,13,16]$.

Second, sleep time was not differentiated from awake time for total AC. MET during sleep time was included in the activity diary by multiplying sleep time with $0.9 \mathrm{MET} / \mathrm{min}$. in accordance with the Compendium of Physical Activities Tracking Guide [28], but this calculation assumes a constant sleep pattern. A disturbed sleep pattern is common in patients with CFS [51], which could (partially) account for the lower correlation between both measures, since higher AC would be registered by the Actical during sleep time, but not in the activity diary. Future research should therefore investigate whether a disturbed sleep pattern influences the relationship between the self-reported and objectively measured PAL or differentiate between awake and sleep time to control for this possible influence $[7,8,27]$.

Because this study is a secondary analysis of previously gathered data, the sample size was not determined based on an a priori power analysis for the current analysis. Therefore, the power of this study cannot be reported.

The generalizability of the current research findings to the overall CFS population is also limited. Because of the statistical methods used, systematic bias of the activity diary cannot be excluded, and the lack of associations with the discrepancy only applies to this sample and not necessarily to male patients. Additional research using the same output variable for the self-report and objective measure with consideration of mentioned points of attention and recommendations should be performed to allow direct comparison between both measures, explore their level of agreement and investigate systematic bias of the activity diary $[11,50]$. Additionally, a higher accuracy for self-report for males than females was identified in healthy controls [11], which should be further investigated in patients with CFS.

\section{Conclusion}

The activity diary used in this study showed limited ability to register the PAL in female patients with CFS. Discrepancies between self-report and objective activity monitoring in patients with CFS relative to healthy controls could not be explained by illness-related complaints, health related quality of life or demographic factors. The activity diary cannot replace objective activity monitoring measured with a motion sensor, but may provide additional information about the perceived activity. Future research should explore the discrepancy between selfreport and direct measures of PA and associated factors further and identify a self-report measure that encompasses detailed information about patients' perceived PAL complementary to a direct measure.

Supplementary data to this article can be found online at https://doi. org/10.1016/j.jpsychores.2021.110417.

\section{Declarations of interest}

The authors have no competing interests to report.

\section{References}

[1] G.P. Holmes, J.E. Kaplan, N.M. Gantz, et al., Chronic fatigue syndrome: a working case definition, Ann. Intern. Med. 108 (3) (1988) 387-389, https://doi.org/ 10.7326/0003-4819-108-3-387.

[2] K. Fukuda, S.E. Straus, I. Hickie, M.C. Sharpe, J.G. Dobbins, A. Komaroff, The chronic fatigue syndrome: a comprehensive approach to its definition and study. International chronic fatigue syndrome study group, Ann. Intern. Med. 121 (12) (1994) 953-959, https://doi.org/10.7326/0003-4819-121-12-199412150-00009.

[3] R.M. Evering, M.G. van Weering, K.C. Groothuis-Oudshoorn, M.M. VollenbroekHutten, Daily physical activity of patients with the chronic fatigue syndrome: a systematic review, Clin. Rehabil. 25 (2) (2011) 112-133, https://doi.org/10.1177/ 0269215510380831.

[4] M.L. Joustra, W.L. Zijlema, J.G.M. Rosmalen, K.A.M. Janssens, Physical activity and sleep in chronic fatigue syndrome and fibromyalgia syndrome: associations with symptom severity in the general population cohort LifeLines, Pain Res. Manag. 5801510 (2018), https://doi.org/10.1155/2018/5801510.

[5] J.L. Newton, J. Pairman, K. Hallsworth, S. Moore, T. Plötz, M.I. Trenell, Physical activity intensity but not sedentary activity is reduced in chronic fatigue syndrome and is associated with autonomic regulation, QJM 104 (8) (2011) 681-687, https://doi.org/10.1093/qjmed/hcr029.

[6] W.J. Kop, A. Lyden, A.A. Berlin, K. Ambrose, C. Olsen, R.H. Gracely, D.A. Williams, D.J. Clauw, Ambulatory monitoring of physical activity and symptoms in fibromyalgia and chronic fatigue syndrome, Arthritis Rheum. 52 (1) (2005) 296-303, https://doi.org/10.1002/art.20779.

[7] S.P. van der Werf, J.B. Prins, J.H. Vercoulen, J.W. van der Meer, G. Bleijenberg, Identifying physical activity patterns in chronic fatigue syndrome using actigraphic assessment, J. Psychosom. Res. 49 (5) (2000) 373-379, https://doi.org/10.1016/ s0022-3999(00)00197-5.

[8] D.C. Vos-Vromans, I.P. Huijnen, A.J. Köke, H.A. Seelen, J.A. Knottnerus, R. J. Smeets, Differences in physical functioning between relatively active and passive patients with chronic fatigue syndrome, J. Psychosom. Res. 75 (3) (2013) 249-254, https://doi.org/10.1016/j.jpsychores.2013.05.001.

[9] E. Bazelmans, J. Prins, G. Bleijenberg, Cognitive behavior therapy for relatively active and for passive chronic fatigue syndrome patients, Cogn. Behav. Pract. 13 (2) (2006) 157-166, https://doi.org/10.1016/j.cbpra.2006.02.001.

[10] G. Plasqui, K.R. Westerterp, Physical activity assessment with accelerometers: an evaluation against doubly labeled water, Obesity (Silver Spring) 15 (10) (2007) 2371-2379, https://doi.org/10.1038/oby.2007.281.

[11] S.A. Prince, K.B. Adamo, M.E. Hamel, J. Hardt, S.C. Gorber, M. Tremblay, A comparison of direct versus self-report measures for assessing physical activity in adults: a systematic review, Int. J. Behav. Nutr. Phys. 5 (2008) 56, https://doi.org/ 10.1186/1479-5868-5-56.

[12] M. Meeus, I. van Eupen, J. Willems, D. Kos, J. Nijs, Is the international physical activity questionnaire-short form (IPAQ-SF) valid for assessing physical activity in chronic fatigue syndrome? Disabil. Rehabil. 33 (1) (2011) 9-16, https://doi.org/ 10.3109/09638288.2010.483307.

[13] A.P. Hills, N. Mokhtar, N.M. Byrne, Assessment of physical activity and energy expenditure: an overview of objective measures, Front. Nutr. 1 (2014) 5, https:// doi.org/10.3389/fnut.2014.00005.

[14] S. Duncan, T. Stewart, M.B. Schneller, S. Godbole, K. Cain, J. Kerr, Convergent validity of ActiGraph and Actical accelerometers for estimating physical activity in 
adults, PLoS One 13 (6) (2018), e0198587, https://doi.org/10.1371/journal. pone.0198587.

[15] R.P. Troiano, J.J. McClain, R.J. Brychta, K.Y. Chen, Evolution of accelerometer methods for physical activity research, Br. J. Sports Med. 48 (13) (2014) 1019-1023, https://doi.org/10.1136/bjsports-2014-093546.

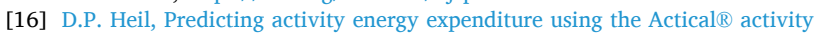
monitor, Res. Q. Exerc. Sport 77 (1) (2006) 64-80.

[17] N.M. Kayes, P.J. Schluter, K.M. McPherson, M. Leete, G. Mawston, D. Taylor, Exploring Actical accelerometers as an objective measure of physical activity in people with multiple sclerosis, Arch. Phys. Med. Rehabil. 90 (4) (2009) 594-601, https://doi.org/10.1016/j.apmr.2008.10.012.

[18] J.H. Vercoulen, E. Bazelmans, C.M. Swanink, J.F. Fennis, J.M. Galama, P.J. Jongen, O. Hommes, J.W.M. Van der Meer, G. Bleijenberg, Physical activity in chronic fatigue syndrome: assessment and its role in fatigue, J. Psychiatr. Res. 31 (6) (1997) 661-673, https://doi.org/10.1016/s0022-3956(97)00039-3.

[19] S.J. Cockshell, J.L. Mathias, Cognitive functioning in chronic fatigue syndrome: a meta-analysis, Psychol. Med. 40 (8) (2010) 1253-1267, https://doi.org/10.1017/ S0033291709992054.

[20] A.M. Fry, M. Martin, Fatigue in the chronic fatigue syndrome: a cognitive phenomenon? J. Psychsom. Res. 41 (5) (1996) 415-426, https://doi.org/10.1016/ s0022-3999(96)00190-0.

[21] R. Bize, J.A. Johnson, R.C. Plotnikoff, Physical activity level and health-related quality of life in the general adult population: a systematic review, Prev. Med. 45 (6) (2007) 401-415, https://doi.org/10.1016/j.ypmed.2007.07.017.

[22] N.K. Anokye, P. Trueman, C. Green, T.G. Pavey, R.S. Taylor, Physical activity and health related quality of life, BMC Public Health 12 (1) (2012) 624, https://doi. org/10.1186/1471-2458-12-624.

[23] E.E. Wickel, G.J. Welk, J.C. Eisenmann, Concurrent validation of the Bouchard diary with an Accelerometry-based monitor, Med. Sci. Sports Exerc. 38 (2) (2006) 373-379, https://doi.org/10.1249/01.mss.0000183344.46077.bb.

[24] C.B. Terwee, L.B. Mokkink, M.N.M. van Poppel, M.J.M. Chinapaw, W. van Mechelen, H.C.W. de Vet, Qualitative attributes and measurement properties of physical activity questionnaires: a checklist, Sports Med. 40 (2010) 525-537, https://doi.org/10.2165/11531370-000000000-00000.

[25] M.S. Bernstein, A. Morabia, D. Sloutskis, Definition and prevalence of sedentarism in an urban population, Am. J. Public Health 89 (6) (1999) 862-867, https://doi org/10.2105/ajph.89.6.862.

[26] L.B. Sardinha, P.B. Júdice, Usefulness of motion sensors to estimate energy expenditure in children and adults: a narrative review of studies using DLW [published correction appears in Eur J Clin Nutr. 2017 Aug;71(8):1026], Eur. J. Clin. Nutr. 71 (3) (2017) 331-339, https://doi.org/10.1038/ejcn.2017.2.

[27] E. King, M. Beynon, T. Chalder, M. Sharpe, P.D. White, Patterns of daytime physical activity in patients with chronic fatigue syndrome, J. Psychosom. Res. 135 (2020) 110154, https://doi.org/10.1016/j.jpsychores.2020.110154.

[28] B.E. Ainsworth, W.L. Haskell, A.S. Leon, D.R. Jacobs Jr., H.J. Montoye, J.F. Sallis, Compendium of physical activities: classification of energy costs of human physical activities, Med. Sci. Sports Exerc. 25 (2003) 71-80.

[29] J. Nijs, A. Thielemans, Kinesiophobia and symptomatology in chronic fatigue syndrome: a psychometric study of two questionnaires, Psychol. Psychother. 81 (Pt3) (2008) 273-283, https://doi.org/10.1348/147608308X306888.

[30] J. Nijs, A. Aerts, K. De Meirleir, Generalized joint hypermobility is more common in chronic fatigue syndrome than in healthy control subjects, J. Manipulative Physiol. Ther. 29 (1) (2006) 32-39, https://doi.org/10.1016/j.jmpt.2005.11.004.

[31] M.E. Wewers, N.K. Lowe, A critical review of visual analogue scales in the measurement of clinical phenomena, Res. Nurs. Health 13 (4) (1990) 227-236, https://doi.org/10.1002/nur.4770130405.

[32] B.K. Crawford, E.C. Piault, C. Lai, R.M. Bennett, Assessing fibromyalgia-related fatigue: content validity and psychometric performance of the fatigue visual analogue scale in adult patients with fibromyalgia, Clin. Exp. Rheumatol. 29 (6 Suppl. 69) (2011) 34-43.

[33] M. Sendlbeck, E.G. Araujo, G. Schett, M. Englbrecht, Psychometric properties of three single-item pain scales in patients with rheumatoid arthritis seen during routine clinical care: a comparative perspective on construct validity, reproducibility and internal responsiveness, RMD Open. 18 (1) (2015), e000140, https://doi.org/10.1136/rmdopen-2015-000140.

[34] J.E. Ware Jr., C.D. Sherbourne, The MOS 36-item short-form health survey (SF-36). I. Conceptual framework and item selection, Med. Care 30 (6) (1992) 473-483.
[35] N.K. Aaronson, M. Muller, P.D. Cohen, M. Essink-Bot, M. Fekkes, R. Sanderman, M. A. Sprangers, A. te Velde, E. Verrips, Translation, validation, and norming of the Dutch language version of the SF-36 health survey in community and chronic disease populations, J. Clin. Epidemiol. 51 (11) (1998) 1055-1068, https://doi. org/10.1016/s0895-4356(98)00097-3.

[36] S.G. Trost, Pate R.R. Freedson PS, J.F. Sallis, W.C. Taylor, Using objective physical activity measures with youth: how many days of monitoring are needed? Med. Sci. Sports Exerc. 32 (2) (2000) 426-431, https://doi.org/10.1097/00005768200002000-00025.

[37] J.D. Storey, R. Tibshirani, Statistical significance for genomewide studies, Proc. Natl. Acad. Sci. U. S. A. 100 (16) (2003) 9440-9445, https://doi.org/10.1073/ pnas.1530509100.

[38] J.F. Wiborg, H. Knoop, M. Stulemeijer, J.B. Prins, G. Bleijenberg, How does cognitive behaviour therapy reduce fatigue in patients with chronic fatigue syndrome? The role of physical activity, Psychol. Med. 40 (8) (2010) 1281-1287, https://doi.org/10.1017/S0033291709992212.

[39] G. McPhee, Cognitive behaviour therapy and objective assessments in chronic fatigue syndrome, J. Health Psychol. 22 (9) (2017) 1181-1186, https://doi.org/ 10.1177/1359105317707215.

[40] E. Bazelmans, G. Bleijenberg, M.J. Voeten, J.W. van der Meer, H. Folgering, Impact of a maximal exercise test on symptoms and activity in chronic fatigue syndrome, J. Psychosom. Res. 59 (4) (2005) 201-208, https://doi.org/10.1016/j. jpsychores.2005.04.003.

[41] E. Cvejic, C.X. Sandler, A. Keech, B.K. Barry, A.R. Lloyd, U. Vollmer-Conna, Autonomic nervous system function, activity patterns, and sleep after physical or cognitive challenge in people with chronic fatigue syndrome, J. Psychosom. Res. 103 (2017 Dec) 91-94, https://doi.org/10.1016/j.jpsychores.2017.10.010.

[42] J.B. Prins, J.W. van der Meer, G. Bleijenberg, Chronic fatigue syndrome, Lancet 367 (9507) (2006) 346-355, https://doi.org/10.1016/S0140-6736(06)68073-2.

[43] J.B. Prins, G. Bleijenberg, E. Bazelmans, et al., Cognitive behaviour therapy for chronic fatigue syndrome: a multicentre randomised controlled trial, Lancet 357 (9259) (2001) 841-847, https://doi.org/10.1016/S0140-6736(00)04198-2.

[44] G.F. Dunton, C.K. Whalen, D.L. Jamner, B. Henker, J.N. Floro, Using ecologic momentary assessment to measure physical activity during adolescence, Am. J. Prev. Med. 29 (4) (2005) 281-287, https://doi.org/10.1016/j. amepre.2005.07.020.

[45] I.P.J. Huijnen, J.A. Verbunt, M.L. Peters, P. Delespaul, H.P.J. Kindermans, J. Roelofs, M. Goossens, H.A. Seelen, Do depression and pain intensity interfere with physical activity in daily life in patients with chronic low Back pain? Pain 150 (1) (2010) 161-166, https://doi.org/10.1016/j.pain.2010.04.021.

[46] F. Schuch, D. Vancampfort, J. Firth, S. Rosenbaum, P. Ward, T. Reichert, N. C. Bagatini, R. Bgeginski, B. Stubbs, Physical activity and sedentary behavior in people with major depressive disorder: a systematic review and meta-analysis, J. Affect. Disord. 210 (2017) 139-150, https://doi.org/10.1016/j. jad.2016.10.050. Erratum in: J Affect Disord. 2018 Jan 1;225:79. PMID: 28033521.

[47] B. Stubbs, A. Koyanagi, M. Hallgren, J. Firth, J. Richards, F. Schuch, S. Rosenbaum, J. Mugisha, N. Veronese, J. Lahti, D. Vancampfort, Physical activity and anxiety: a perspective from the world health survey, J. Affect. Disord. 208 (2017) 545-552, https://doi.org/10.1016/j.jad.2016.10.028.

[48] P. Freedson, H.R. Bowles, R. Troiano, W. Haskell, Assessment of physical activity using wearable monitors: recommendations for monitor calibration and use in the field, Med. Sci. Sports Exerc. 44 (1Suppl1) (2012), https://doi.org/10.1249/ MSS.0b013e3182399b7e. S1-4.

[49] J. Nijs, S. Aelbrecht, M. Meeus, J. Van Oosterwijck, E. Zinzen, P. Clarys, Tired of being inactive: a systematic literature review of physical activity, physiological exercise capacity and muscle strength in patients with chronic fatigue syndrome, Disabil. Rehabil. 33 (17-18) (2011) 1493-1500, https://doi.org/10.3109/ 09638288.2010 .541543$.

[50] G.J. Welk, J. McClain, B.E. Ainsworth, Protocols for evaluating equivalency of accelerometry-based activity monitors, Med. Sci. Sports Exerc. 44 (1Suppl1) (2012) S39-S49, https://doi.org/10.1249/MSS.0b013e3182399d8f.

[51] Z.M. Gotts, V. Deary, J.L. Newton, J.G. Ellis, A comparative polysomnography analysis of sleep in healthy controls and patients with chronic fatigue syndrome, Fatigue 4 (2) (2016) 80-93, https://doi.org/10.1080/21641846.2016.1167470. 